\title{
Phosphorus Adsorption and Nitric Acid Reduction by Ferrous Sulfate-Treated Foamed Waste Glass
}

\section{Asmak Afiliana1, Harada Hiroyuki ${ }^{*}$, Katayama Yumi ${ }^{1}$, Nishikawa Hanami ${ }^{1}$, Mitoma Yoshiharu1, Tomoyuki Miyamoto²}

\author{
${ }^{1}$ Faculty of Environmental Science, Prefectural University of Hiroshima, Hiroshima, Japan \\ ${ }^{2}$ Recycle Center, COCCO Co., Kure City, Hiroshima \\ Email: ^ho-harada@pu-hiroshima.ac.jp
}

How to cite this paper: Afiliana, A., Hiroyuki, H., Yumi, K., Hanami, N., Yoshiharu, M. and Miyamoto, T. (2018) Phosphorus Adsorption and Nitric Acid Reduction by Ferrous Sulfate-Treated Foamed Waste Glass. Journal of Materials Science and Chemical Engineering, 6, 21-30. https://doi.org/10.4236/msce.2018.63002

Received: January 30, 2018

Accepted: March 16, 2018

Published: March 19, 2018

Copyright $\odot 2018$ by authors and Scientific Research Publishing Inc. This work is licensed under the Creative Commons Attribution International License (CC BY 4.0).

http://creativecommons.org/licenses/by/4.0/

\begin{abstract}
Wastewaters containing phosphorus and nitric acid are produced during biological treatment processes. In this study, a material for treating such wastewaters was developed. Foamed glass was produced from waste glass and then heated with iron sulfate to prepare an adsorbent for phosphorus and carrier for reducing nitric acid. The adsorbent performance was evaluated in batch and continuous experiments. The saturated adsorption amount of phosphate was $6.23 \mathrm{mg} / \mathrm{g}$ for the product obtained from glass of size 3 to $12 \mathrm{~mm}$; the amount adsorbed was relatively high, in spite of the large glass size. The denitrification by reduction of nitrate was around $25 \%$.
\end{abstract}

\section{Keywords}

Foamed Waste Glass, Iron Loaded, Adsorbent, Phosphorus Recovery, Continuous Column Experiment

\section{Introduction}

Phosphorus in wastes such as domestic and industrial wastewaters, and livestock excrement can cause water pollution and eutrophication of water systems. This problem is dealt with by legislation covering areas such as water pollution control and special measures regarding lake water quality conservation, and setting emission standards for phosphate. In closed waters such as lakes, phosphorus accumulation and eutrophication are increasing. Phosphorus ores will be exhausted in about 80 years [1].

The development of phosphorus-recycling systems would help to counteract 
phosphorus depletion. The introduction of phosphate-adsorbing materials into systems such as domestic and industrial wastewaters, and sewage, which are sources of eutrophication, would enable recovery of phosphorus released into aqueous systems. This would reduce the amount of phosphorus in water systems and the recovered phosphate adsorbent could be added to soil and reused as phosphate fertilizer. Foamed glass materials have a porous structure that incorporates a large number of voids and are conventionally used as civil engineering materials or aggregates for construction [2]. Since calcium carbonate is used as the foaming agent, and it can be used as an adsorbent for phosphorus. Not only the surface but also the internal voids of a porous material provide adsorption sites. Foamed glass therefore has advantages as an adsorbent, and the phosphorus-adsorbing ability can be enhanced by adjusting the constituents. However, there have been few studies of the phosphorus-adsorbing capacities of porous materials [3]. In this study, we investigated the effects on adsorption of ferrous ion loading, with the aim of increasing the phosphorus adsorption capacity. Several methods for preparing adsorbents consisting of iron supported on a porous base material have been reported. In most cases, porous carbon has been used as the base material, and, to the best of our knowledge, there has been no report of the use of foamed glass [4] [5]. It is easy to adjust the particle diameter and specific gravity of foamed glass, therefore phosphorus adsorbents for various purposes can be prepared. In Japan, there are no phosphorus resources; therefore phosphorus recovery with foamed glass is attractive. The effect of the calcium component is important. Foamed glass saturated with adsorbed phosphorus can be used directly as a fertilizer [3]. In this case, desorption is necessary because iron is loaded to increase adsorption capacity. However, the reducing effect of iron of nitrate reduction can be expected by loaded iron [6] [7]. In this study, we investigated phosphorus and nitrate ion removal from environmental water using iron-loaded foamed glass.

\section{Materials and Experimental Methods}

\subsection{Materials}

The samples of foamed glass tested in this study were collected from a production site in Kure City, Hiroshima, Japan. First of all, waste glass is collected and finely crushed. Add calcium carbonate to it and heat it at $800^{\circ} \mathrm{C}-900^{\circ} \mathrm{C}$. Carbon dioxide gas comes out and becomes a porous material.

Table 1 shows the average composition of the product, determined by an official agency, according to a standard method (Japan Industrial Standards method JIS G 1257). The pore size distribution in the products used for the experiments varied; it has been reported that the distribution depends on the foaming material and treatment temperature. Kazmina reported pore sizes in the range 1 - 4 $\mu \mathrm{m}$ [7]. The average specific density of the samples in this study was $0.42 \mathrm{~g} / \mathrm{cm}^{3}$ (dry bulk density, dry weight basis), determined with a pycnometer. Other physical and mechanical strength characteristics are shown in Table 2. This is 
Table 1. Foamed glass composition.

\begin{tabular}{cc}
\hline Ingredients & Content [\%] \\
\hline $\mathrm{SiO}_{2}$ & 71 \\
$\mathrm{CaO}$ & 10.9 \\
$\mathrm{Na}_{2} \mathrm{O}$ & 13.2 \\
$\mathrm{Al}_{2} \mathrm{O}_{3}$ & 1.76 \\
$\mathrm{~K}_{2} \mathrm{O}$ & 1.11 \\
$\mathrm{MgO}$ & 0.20 \\
\hline
\end{tabular}

Table 2. The main physical and mechanical characteristics of the product.

\begin{tabular}{cccc}
\hline $\begin{array}{c}\text { Bulk dry } \\
\text { Density }\left[\mathrm{t} / \mathrm{m}^{3}\right]\end{array}$ & Water absorption [\%] & Length [mm] & Average CBR \% \\
\hline $\mathbf{0 . 4 2}$ & Average $30 \%$ & $2-75 \mathrm{~mm}$ & 30.9 \\
\hline
\end{tabular}

the measurement results based on the standard soil test method [JIS]. The specific gravity lightly floats on water and shows strength against load.

Methods for supporting iron include using starch as an adhesive and heating at $105^{\circ} \mathrm{C}$ [8] [9]. In this study, the heating method was used. Figure 1 shows a photograph of foamed glass of diameter $14-25 \mathrm{~mm}$. Foamed glass $(5 \mathrm{~g})$ was placed in $0.2 \mathrm{~mol} / \mathrm{L}$ ferrous sulfate solution $(200 \mathrm{~mL})$ and the mixture was heated continuously at $105^{\circ} \mathrm{C}$ for $48 \mathrm{~h}$ under gentle stirring at $40 \mathrm{rpm}$, using a laboratory stirrer with a hotplate (ASONE Co., Tornado). After thorough washing with tap water, the product was dried and used in the experiments. Figure 2 shows a scanning electron microscopy (SEM) image of the surface and energy-dispersive $\mathrm{X}$-ray spectroscopy (EDX) results. The analysis was performed with a $6610 \mathrm{~A}$ instrument (JEOL Ltd.) Iron was loaded on foamed glass of length $3-12 \mathrm{~mm}$, and the glass was crushed for analysis. X-ray diffraction (XRD) showed that iron was distributed uniformly on the surface.

\subsection{Treatment Conditions}

\subsubsection{Effect of Initial pH (Batch Experiments)}

1) Phosphorus adsorption

A model environmental water sample with a phosphate concentration of 5 ppm was prepared using a $0.1 \mathrm{M}$ dihydrogen phosphate solution and its initial $\mathrm{pH}$ was adjusted from 1 to 7 with $0.1 \mathrm{M}$ sulfuric acid and sodium hydroxide solution. The solution $(40 \mathrm{~mL})$ and the adsorbent $(2 \mathrm{~g})$, i.e., a liquid/solid ratio of $20 \mathrm{~mL} / \mathrm{g}$, were placed in a $50 \mathrm{~mL}$ centrifuge tube in a small rotating agitator (TAITEC RT-50) in a thermostatic chamber at $30^{\circ} \mathrm{C}$. Agitation was performed at $40 \mathrm{rpm}$ for $24 \mathrm{~h}$. After separation, filtration was performed with 5 type $\mathrm{C}$ filter paper, and the phosphate in the filtrate was determined by molybdenum blue spectrophotometry, according to APHA method 4500-P B. All reagents were special grade and purchased from Wako Ltd. 


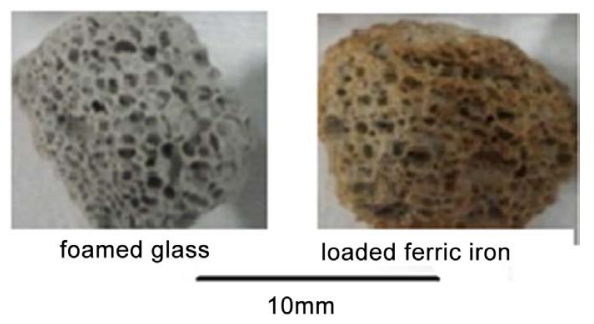

Figure 1. Photographs of foamed glass and iron-loaded foamed glass.
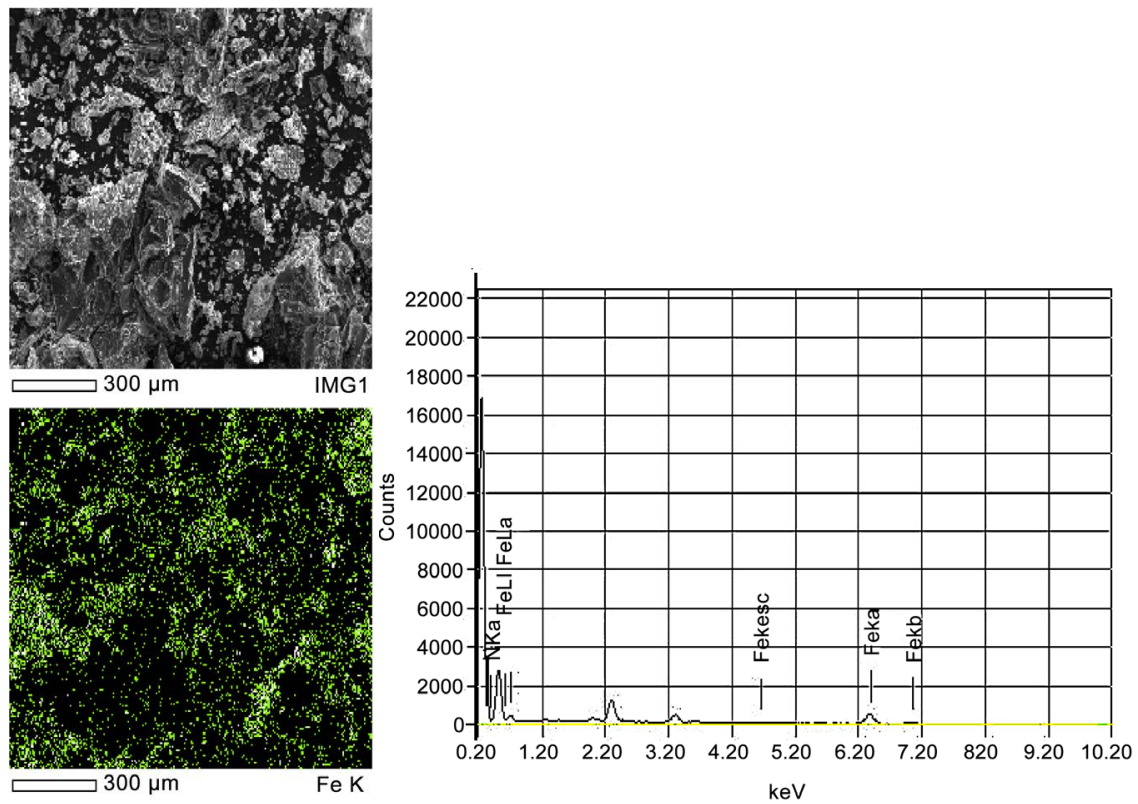

Figure 2. SEM image and EDX analysis of surface.

\section{2) Nitrate removal}

A model environmental water sample with a nitrate ion concentration of 20 ppm was prepared using $0.1 \mathrm{M}$ nitric acid solution and the initial $\mathrm{pH}$ was adjusted from 4 to 6 with sodium hydroxide solution. The solution $(40 \mathrm{~mL})$ and the adsorbent $(2 \mathrm{~g})$ were placed in a $50 \mathrm{~mL}$ centrifuge tube, i.e., a liquid/solid ratio of $20 \mathrm{~mL} / \mathrm{g}$, in a small rotating agitator (TAITEC RT-50) in a thermostatic chamber at $30^{\circ} \mathrm{C}$. Agitation was performed at $40 \mathrm{rpm}$ for $24 \mathrm{~h}$. After separation, filtration was performed with 5 type $\mathrm{C}$ filter paper, and the nitrate in the filtrate was determined by $N$-(1-naphthyl) ethylenediamine dihydrochloride spectrophotometry, according to EPA method 352. All reagents were special grade and purchased from Wako Ltd.

\subsubsection{Desorption (Batch Experiments)}

1) Phosphate

The desorption of adsorbed phosphorus by anion exchange with hydroxyl ions can be achieved with sodium hydroxide solution of $\mathrm{pH} 12$. The first step in the procedure was adsorption of a $100 \mathrm{mg} / \mathrm{L}$ phosphoric acid solution. The recovered adsorbent was washed with distilled water and dried at $60^{\circ} \mathrm{C}$ for $2 \mathrm{~h}$. The adsorbent was immersed in sodium hydroxide solution of $\mathrm{pH} 12$. Because of the 
high alkalinity, the immersion time was shortened to $4 \mathrm{~h}$, and the operation was repeated under the same experimental conditions.

\subsubsection{Continuous Treatment Experiment}

1) Phosphate adsorption and nitrate removal

The experimental setup is shown in Figure 3. Iron-loaded foamed glass was loaded into a pressure-resistant glass column of diameter $1 \mathrm{~cm}$ and length $30 \mathrm{~cm}$, so that the glass was filled to $15 \mathrm{~cm}$ from the top of the column. Raw water was supplied from the bottom to obtain treated water.

At the sampling time, the effluent volume was measured, and filtration was performed with 5 type $\mathrm{C}$ filter paper prior to analysis. A raw water sample with suspended solid concentration $18 \mathrm{mg} / \mathrm{L}, \mathrm{pH} 4.2$, phosphate concentration 4.80 $\mathrm{mg} / \mathrm{L}$, and nitrate nitrogen concentration $1.0 \mathrm{mg} / \mathrm{L}$ was obtained from a wastewater treatment facility at the Prefectural University of Hiroshima and used for this experiment. All reagents were special grade and purchased from Wako Ltd.

\section{Results and Discussion}

\subsection{Batch Experiments}

1) Phosphate

Figure 4 shows the effect of the initial $\mathrm{pH}$ on the adsorption rate. The rate was $80 \%$ or more at $\mathrm{pH} 2,97 \%$ to $90 \%$ at $\mathrm{pH} 3-6$, and fell to $80 \%$ at $\mathrm{pH} 7$. The difference between the initial $\mathrm{pH}$ and the equilibrium $\mathrm{pH}$ after the reaction was within 0.3 . In this $\mathrm{pH}$ range, the main ions present were dihydrogen phosphate and hydrogen phosphate. These ionic phosphorus-containing species reacted with hydrated iron. The hydroxide ions hydrates to the iron on foamed waste glass and exchanges with phosphorus at the time of adsorption. The form of phosphorus at this time are to be a monohydrogenphosphate ion or a dihydrogen phosphate ion depending on the $\mathrm{pH}$. Therefore, hydroxyl ions and monohydrogen phosphate ions are exchanged in equal amounts, or two hydroxyl ions and dihydrogen phosphate ions are exchanged [10]. The results suggest that the ionic phosphorus species reacted with hydrated iron. On desorption, phosphorus and hydroxide ion are exchanged in an alkaline state.

Isothermal adsorption experiments were performed at an initial $\mathrm{pH}$ of 4 ; the same method as that described above was used. The amount of material adsorbed per gram of adsorbent $(y)$ was calculated from the difference between the concentrations before and after treatment, the treatment volume, and the equilibrium concentration (c). The values of $1 / c$ and $c y$ were obtained from the Langmuir equation, and monomolecular layer adsorption was assumed:

$$
c / y=1 /\left(b y_{m}\right)+c / y_{m}
$$

$y_{m}$ : amount of solute adsorbed on the adsorbent $(\mathrm{mg} / \mathrm{g})$.

c. phosphate concentration of solution at adsorption equilibrium $(\mathrm{mg} / \mathrm{L})$.

$y_{m}$ : amount of solute necessary for monomolecular layer formation $(\mathrm{mg} / \mathrm{g})$.

$b$ : constant. 


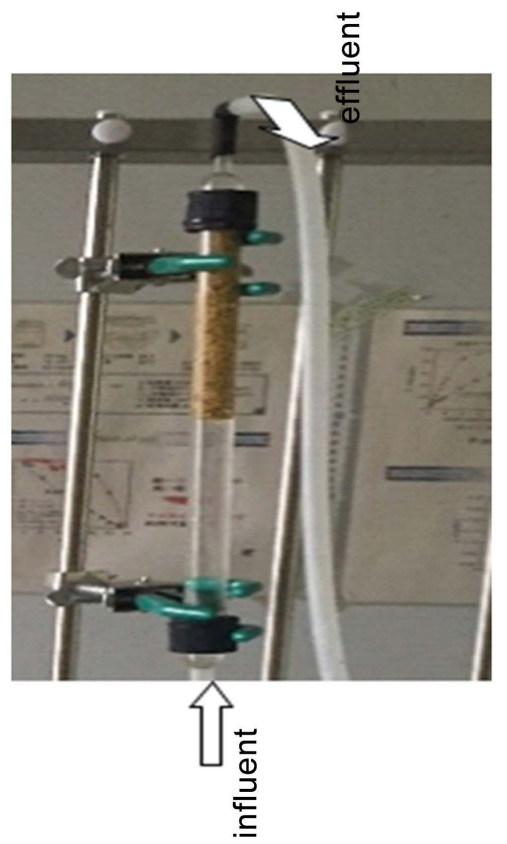

Figure 3. Experimental setup for continuous treatment.

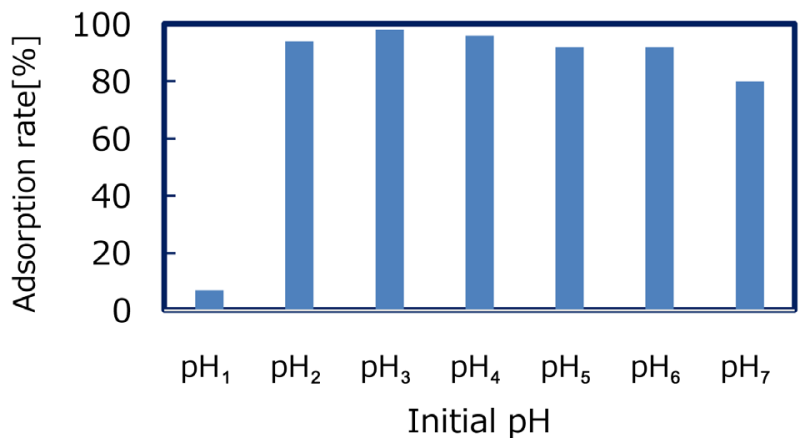

Figure 4. Effects of initial $\mathrm{pH}$ on phosphate.

Figure 5 shows the results obtained by fitting the isothermal adsorption data to Equation (1). The saturated adsorption amount, calculated from the slope of the plot, was $6.25 \mathrm{mg}$. Table 3 shows the saturated adsorption amounts for various adsorbents. Iron loading increased the saturated adsorption capacity 8.3 -fold. The results indicate that the factory product lot used in this research had a high phosphorus adsorption capacity, despite its large size.

Figure 6 shows the desorption results. Although the effect of the liquid/solid ratio was small on desorption was slightly .The desorption ratio was reached $84 \%$ at $30 \mathrm{~mL} / \mathrm{g}$. Most desorption occurred during the first operation. However, the influence of the solid-liquid ratio was small, and there was no tendency that the amount of desorption depended on the solid-liquid ratio. This seems not only that the adsorption of phosphorus is caused by ion exchange.

2) Nitrate

Figure 7 show the effect of the initial $\mathrm{pH}$ on the nitrate nitrogen reduction to ammonium nitrogen. The results show that nitrate ions were reduced and 


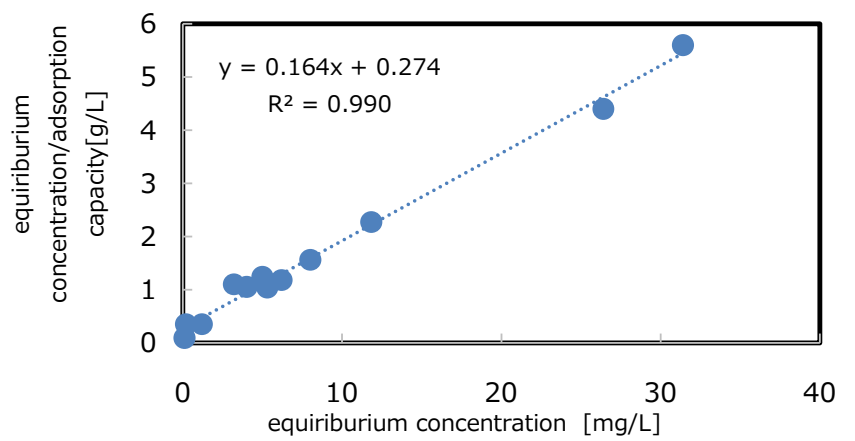

Figure 5. Isothermal adsorption equation.

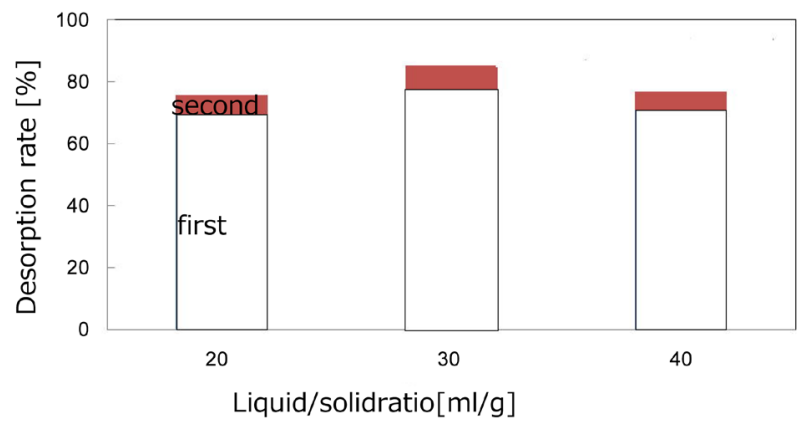

Figure 6. Effects of liquid/solid ratio on desorption rate.

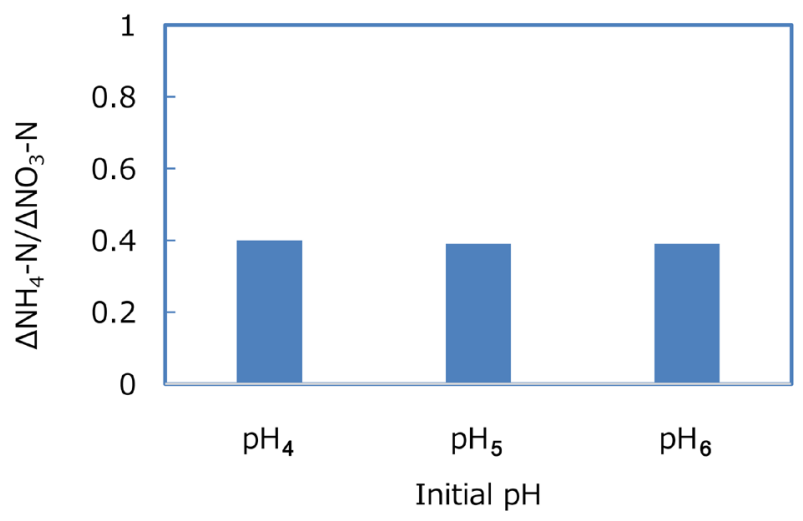

Figure 7. Effects of initial $\mathrm{pH}$ on nitrate reduction.

Table 3. Phosphorus adsorption capacities of various adsorbents.

\begin{tabular}{cccc}
\hline \multicolumn{1}{c}{ Adsorbent } & $\begin{array}{c}\text { Maximum adsorption } \\
\text { capacity * point }\end{array}$ & $\begin{array}{c}\text { Diameter or } \\
\text { length }\end{array}$ & reference \\
\hline 1) Fe (III) loaded okara & $4.78 \mathrm{mg} / \mathrm{g}$ & $0.15 \mathrm{~mm}$ & {$[11]$} \\
2) Foamed glass (not Fe-loaded) & $3.60 \mathrm{mg} / \mathrm{g}$ & $1 \mathrm{~mm}-0.15 \mathrm{~mm}$ & {$[2]$} \\
*added $\mathrm{Na}_{2} \mathrm{CO}_{3}$ and CaMg $\left.\left(\mathrm{CO}_{3}\right)_{2}\right) 10 \%$ & $0.45 \mathrm{mg} / \mathrm{g}$ & $1 \mathrm{~mm}-0.15 \mathrm{~mm}$ & {$[12]$} \\
3) This study & & & \\
Foamed glass (Factory products) & $2.07 \mathrm{mg} / \mathrm{g}$ & $3 \mathrm{~mm}-12 \mathrm{~mm}$ & \\
${ }^{*}$ Fe-loaded & $1.0 \mathrm{mg} / \mathrm{g}$ & $10 \mathrm{~mm}-20 \mathrm{~mm}$ & \\
${ }^{*}$ not Fe-loaded & $0.75 \mathrm{mg} / \mathrm{g}$ & $3 \mathrm{~mm}-12 \mathrm{~mm}$ & \\
\hline
\end{tabular}


ammonium ions were produced. The nitrogen ratio was about $0.4: 1$, regardless of $\mathrm{pH}$. The initial nitrate ion concentration, i.e., $20 \mathrm{mg} / \mathrm{L}$, decreased to 14.2 $\mathrm{mg} / \mathrm{L} ; 0.7 \mathrm{mg} / \mathrm{L}$ ammonium ion production was observed. The amount of ammonium ion sformed was small, and the denitrification rate was about $25 \%$.

\subsection{Continuous Experiment}

Figure 8 shows changes in nitrogen, phosphate and $\mathrm{pH}$ in treated water in continuous treatment. The nitrogen concentration in the treated water decreased, and then became constant, probably as a result of internal diffusion. The concentration of ammonium ion remained below $0.4 \mathrm{mg} / \mathrm{L}$ during the experiment. Figure 9 shows that many bubbles accumulated in the column, and reduction to nitrogen gas was maintained. Phosphate adsorption reached breakthrough at 40 times the bed volume (BV). In addition, there was almost no difference between the $\mathrm{pH}$ values of the treated and raw waters.
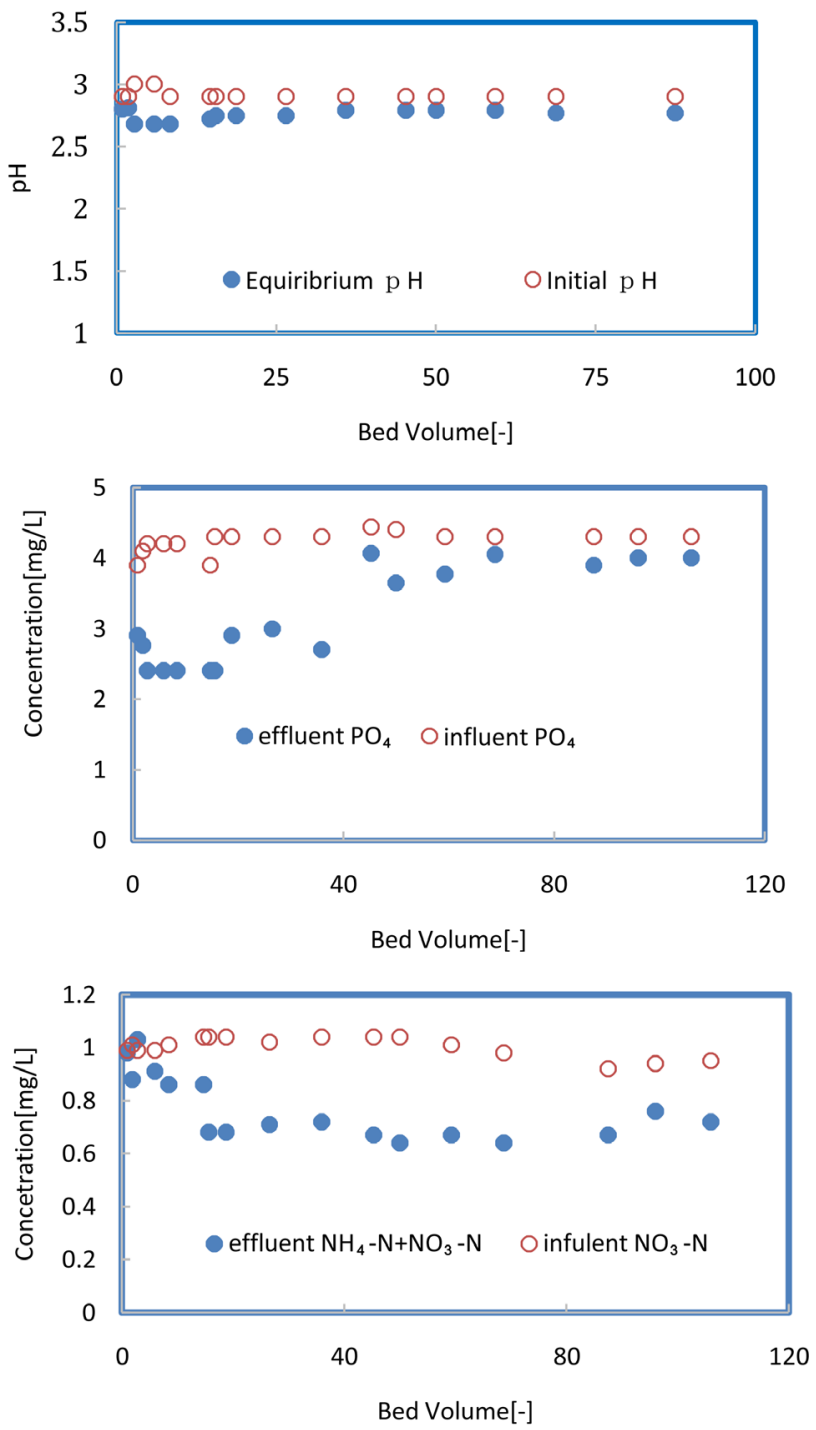

Figure 8. Simultaneously reduction phosphate and nitrogen by column experiment. 


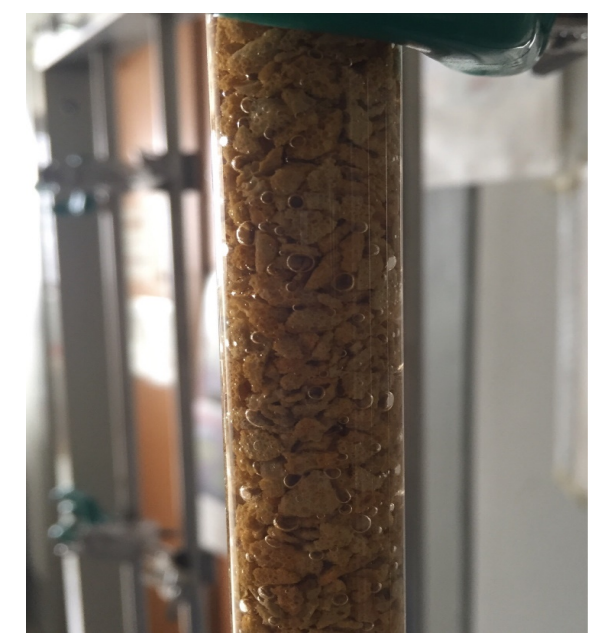

Figure 9. Photograph of column.

\section{Conclusions}

The aim of this study was to prepare phosphorus adsorbents from foamed glass, and to increase the adsorption capacity compared with previously reported values. The adsorbent was prepared by heat-treating the foamed glass base material with an iron sulfate solution, and washing and drying it. The foamed glass material had a specific gravity of 0.42 and two types of product, with diameters of 0.3 to $1.2 \mathrm{~cm}$, were used. An adsorption rate of $97 \%$ was achieved at $\mathrm{pH} 3-4$. The phosphate desorption rate was $84 \%$ at $\mathrm{pH} 12$ and a liquid/solid ratio 30 . Approximately $25 \%$ of the nitrate ions were denitrified at $\mathrm{pH} 4$. Although the amount of ammonium ions was small, it corresponded to $40 \%$ of the nitrogen present. Water from a septic tank at the university was continuously treated in a column; the water contained nitrate $5 \mathrm{mg} / \mathrm{L}$ and phosphate $4 \mathrm{mg} / \mathrm{L}$. Phosphorus breakthrough was reached at BV 40 . A denitrification rate of $30 \%$ was maintained.

Since the foamed waste glass carrier floats in liquids, it is thought that maintenance of clogging and pressure loss by suspension in continuous adsorption becomes easy. We are planning to consider actual waste water adsorption in the future.

\section{Acknowledgements}

This research was funded by the Ministry of Education, Culture, Sports, Science, and Tech-nology, Japan (Grant No. 15K00605). We thank Helen McPherson, $\mathrm{PhD}$, from Edanz Group (www.edanzediting.com/ac) for editing a draft of this manuscript.

\section{References}

[1] Abelson, P.H. (2015) A Potential Phosphate Crisis. Science, 283.

[2] Kazmina, O.V., Tokareva, A.Y. and Vereshchagin, V.I. (2016) Using Quartzofeldspathic Waste to Obtain Foamed Glass Material. Resource-Efficient Technolo- 
gies, 2, 23-29.

[3] Nakazawa, R. and Koyama, H. (2009) Improvement and Characterization of Phosphate-Adsorption Capacity of Porous Glass Materials. Bulletin of TIRI, 4, 2-7. (In Japanese)

[4] Yao, Y., Gao, B., Inyang, M., Zimmerman, A.R., Cao, X.D., Pullammanappallil, P. and Yang, L.Y. (2011) Removal of Phosphate from Aqueous Solution by Biochar Derived from Anaerobically Digested Sugar Beet Tailings. Journal of Hazardous Materials, 190, 501-507. https://doi.org/10.1016/j.jhazmat.2011.03.083

[5] Yang, Q., Wang, X.L., Luo, W., Sun, J., Xu, Q.X., Chen, F., Zhao, J.W., Wang, S., Yao, F.B., Wang, D.B., Li, X.M. and Zeng, G.M. (2018) Effectiveness and Mechanisms of Phosphate Adsorption on Iron-Modified Biochars Derived from Waste Activated Sludge. Bioresource Technology, 247, 537-544.

https://doi.org/10.1016/j.biortech.2017.09.136

[6] Yamashita, M. and Honada, K. (2010) Examination of Utilization of Regeneration Amorphous Iron Oxide for Reduction Catalyst of Nitrate Nitrogen. Journal of Environmental Chemistry, 20, 351-355. (In Japanease)

https://doi.org/10.5985/jec.20.351

[7] Song, X.J., Chen, Z.H., Wang, X.M. and Zhang, S.J. (2017) Ligand Effects on Nitrate Reduction by Zero-Valent Iron: Role of Surface Complexation. Water Research, 114, 218-227. https://doi.org/10.1016/j.watres.2017.02.040

[8] Wang, D., Chen, N., Yu, Y., Hu, W.W. and Feng, C.P. (2016) Investigation on the Adsorption of Phosphorus by $\mathrm{Fe}$-Loaded Ceramic Adsorbent. Journal of Colloid and Interface Science, 464, 277-284. https://doi.org/10.1016/j.jcis.2015.11.039

[9] Su, Y.M., Sun, X.Y., Zhou, X.F., Dai, C.M. and Zhang, Y.L. (2015) Zero-Valent Iron Doped Carbons Readily Developed from Sewage Sludge for Lead Removal from Aqueous Solution. Journal of Environmental Science, 36, 1-8. https://doi.org/10.1016/j.jes.2015.03.018

[10] Jawad, A.H., Islam, Md.A. and Hameed, B.H. (2017) Cross-Linked Chitosan Thin Film Coated onto Glassplate as an Effective Adsorbent for Adsorption of Reactive Orange 16. International Journal of Biological Macromolecules, 95, 743-749. https://doi.org/10.1016/j.ijbiomac.2016.11.087

[11] Nguyen, T.A.H., Ngo, H.H. and Guo, W.S. (2013) Feasibility of Iron Loaded “Okara" for Biosorption of Phosphorous in Aqueous Solutions. Bioresource Technology, 150, 42-49. https://doi.org/10.1016/j.biortech.2013.09.133

[12] Nakazawa, Tomemori, R., Hirano, H., Mochizuki, A., An, H. and Inanaga, P. (2006) Effects of Application of Porous Glass Materials Treated with Phosphate on the Growth of Tomato Plants and Phyto-Available Phosphate in Soil. Soil Science and Plant Nutrition, 52, 540-544. 